\title{
Cold and alone? Roost choice and season affect torpor patterns in lesser short-tailed bats
}

\author{
Zenon J. Czenze ${ }^{1}$ R. Mark Brigham ${ }^{2} \cdot$ Anthony J. R. Hickey $^{1} \cdot$ Stuart Parsons $^{1,3}$
}

Received: 17 May 2016 / Accepted: 16 August 2016 / Published online: 25 August 2016

(C) Springer-Verlag Berlin Heidelberg 2016

\begin{abstract}
Seasonal changes in weather and food availability differentially impact energy budgets of small mammals such as bats. While most thermal physiological research has focused on species that experience extreme seasonal temperature variations, knowledge is lacking from less variable temperate to subtropical climates. We quantified ambient temperature $\left(T_{\mathrm{a}}\right)$ and skin temperature $\left(T_{\mathrm{sk}}\right)$ responses by individuals from a population of New Zealand lesser shorttailed bats (Mystacina tuberculata) during summer and winter using temperature telemetry. During summer, communal roosts were more thermally stable than $T_{\mathrm{a}}$. During winter, solitary roosts were warmer than $T_{\mathrm{a}}$ indicating significant thermal buffering. Communal roost trees were used on $83 \%$ of observation days during summer, and individuals occupying them rarely entered torpor. Solitary roosts were occupied on $93 \%$ of observation days during winter, and $100 \%$ of individuals occupying them used torpor. During summer and winter, bats employed torpor on 11 and $95 \%$ of observation days, respectively. Maximum torpor bout duration
\end{abstract}

Communicated by Christian Voigt.

We show exciting flexibility in seasonal behaviour of a warm temperate mammal. New Zealand bats used a heterothermic continuum, like cold temperate bats, despite mild changes in ambient temperature.

Zenon J. Czenze

zcze255@aucklanduni.ac.nz

1 School of Biological Sciences, University of Auckland, Private Bag 92019, Auckland 1142, New Zealand

2 Department of Biology, University of Regina, Regina, SK, Canada

3 Present Address: School for Earth, Environmental and Biological Sciences, Queensland University of Technology, Brisbane, QLD, Australia was $120.8 \mathrm{~h}$ and winter torpor bout duration correlated negatively with mean $T_{\mathrm{a}}$. Torpor bout duration did not differ between sexes, although female minimum $T_{\text {sk }}$ was significantly lower than males. The summer Heterothermy Index varied, and was also significantly affected by $T_{\mathrm{a}}$. Mean arousal time was correlated with sunset time and arousals occurred most frequently on significantly warmer evenings, which are likely associated with an increased probability of foraging success. We provide the first evidence that torpor is used flexibly throughout the year by $M$. tuberculata, demonstrating that roost choice and season impact torpor patterns. Our results add to the growing knowledge that even small changes in seasonal climate can have large effects on the energy balance of small mammals.

Keywords Torpor $\cdot$ Mystacina tuberculata .

Thermoregulation $\cdot$ Microhabitat $\cdot$ Seasonal weather

\section{Introduction}

All organisms must maintain a positive daily energy balance or they will perish. Energy balance is influenced by precipitation, reproductive state, circannual cycles, photoperiod, food/water availability, and ambient temperature $\left(T_{\mathrm{a}}\right)$ (Csada and Brigham 1994; Song and Geiser 1997; Körtner and Geiser 2000a; b; McNab 2002; Doucette et al. 2012). Ambient temperature has fundamental impacts on metabolism, particularly in small endotherms (i.e. mammals and birds). Maintaining a high and stable body temperature $\left(T_{\mathrm{b}}\right)$ requires large amounts of energy, particularly for small mammals that quickly lose heat to the environment due to their high surface area to volume ratios.

Though individuals living in highly variable temperate climates face the most drastic changes in seasonal 
environment, warm temperate areas also expose individuals to seasonal changes in $T_{\mathrm{a}}$ and presumably energy availability. For most temperate and subtropical endotherms, summer is a period of positive energy balance. During summer, food is usually more abundant than in winter and the costs of thermoregulation at higher $T_{\mathrm{a}}$ are lower. In coldtemperate areas, winter is challenging because endotherms must cope with energy shortages and greater heat loss to the environment. However, the influence of $T_{\mathrm{a}}$ variability in subtropical and warm temperate habitats has been less thoroughly explored.

To minimize energy loss during periods of prolonged energy scarcity, many clades of vertebrates employ daily or multiday torpor (Wang 1989; Grigg et al. 2004; Ruf and Geiser 2015). Torpor is a physiological state characterized by decreases in metabolic rate (MR) leading to reduced $T_{\mathrm{b}}$ (Geiser 2004). Some hibernators accumulate a fat store or food cache large enough to balance energy costs (e.g., Lyman 1982; Geiser 2004). During winter, many of these species decrease energy expenditure so that their reserves are large enough to survive, as even small increases in energy expenditure may negatively impact survival (Speakman et al. 1991; Boyles and Brack 2009; although see Geiser (2007)).

Most species that hibernate periodically arouse, via metabolic heat production to a high, stable $T_{\mathrm{b}}$ (i.e. normothermia), and while periodic arousals are brief, this can account for up to $90 \%$ of overwinter energy expenditure (Wang 1989; Thomas et al. 1990; Geiser 2004). The "torpor optimization hypothesis" postulates that expression of torpor should reflect a balance between the benefits of reduced MR and arousal costs (Humphries et al. 2003; Jonasson and Willis 2011). Furthermore, the torpor optimization hypothesis predicts differences in sex-specific energy budgets for species with differential timing of reproductive investment (Michener 1992; Humphries et al. 2003; Jonasson and Willis 2011).

Lesser short-tailed bats (Mystacina tuberculata) are the only extant species of family Mystacinidae, and this family is endemic to New Zealand. Mystacina tuberculata provide a good model to examine energetic flexibility in small mammals, as they live in areas with more subtle seasonal variations than most temperate mammals. Lesser shorttailed bats roost throughout the year in tree cavities, which may or may not be thermally stable (Sedgeley 2006). Reproductive activity by males peaks during late summer and females give birth the following spring (Daniel 1990). Winter behaviour is generally characterized by inactivity within a tree roost, however, activity is positively correlated with $T_{\mathrm{a}}$ (Daniel 1979; Christie 2003, 2006; Christie and Simpson 2006). Notably, mild winter weather (i.e. above $10{ }^{\circ} \mathrm{C}$ ) increases the abundance of flying insects (Paige 1995), and although M. tuberculata are omnivorous, insects make up the majority of their diet (Arkins et al. 1999).
We used temperature-sensitive radio transmitters on individuals to address thermoregulatory patterns of freeranging $M$. tuberculata in Pureora Forest Park, in the central North Island of New Zealand. Our first hypothesis was that differences in seasonal energy budgets, due to changes in $T_{a}$, would affect roost choice, and we predicted that individuals would choose thermally buffered roost microclimates to save energy. Our second hypothesis was that seasonal variation in $T_{\mathrm{a}}$ influence the frequency, duration, and depth of torpor bouts, and we predicted that warmer $T_{\mathrm{a}}$ during summer would lead individuals to use torpor less than during winter. Furthermore, we predicted that when torpor was used, it would be more frequent, prolonged, and/or deeper during colder days when prey availability is presumably lower. Finally, we examined the hypothesis that timing differences in reproductive investment lead to intersexual differences in winter skin temperature $\left(T_{\text {sk }}\right)$ patterns. Specifically we predicted females, whose reproductive investment comes after winter would be more conservative and exhibit longer and/or deeper torpor bouts than males.

\section{Methods}

All procedures were approved by the University of Auckland Animal Ethics Committee (AEC-R1374) and were conducted under New Zealand Department of Conservation Wildlife Act Authorization Number 39083-FAU. Our study was conducted in the Pikiariki Ecological Area of Pureora Forest Park $\left(38^{\circ} 26^{\prime} \mathrm{S}, 175^{\circ} 39^{\prime} \mathrm{E}\right)$, central North Island, New Zealand, during the Austral "summer" (January-March) and "winter" (June-October). Pikiariki consists of approximately 450 ha of native, mature podocarp-hardwood forests and is home to approximately $700 \mathrm{M}$. tuberculata (Wallace 2006). Bats occupied 15 solitary roosts (housing only one individual), and four communal roosts (housing upwards of 400 individuals at a time).

We caught bats in harp traps and mist nets. Individuals were sexed, aged, weighed to the nearest $0.5 \mathrm{~g}$ using a spring pesola, forearm length was measured to the nearest $1 \mathrm{~mm}$, and we calculated body condition index (BCI), mass $(\mathrm{g})$ forearm length $(\mathrm{mm})^{-1}$. Young of the year were distinguished from adults by the lack of ossification of the metacarpal-phalangeal joint on the third digit (Davis and Hitchcock 1965).

For small bats, $T_{\text {sk }}$ provides a good approximation of $T_{\mathrm{b}}$ (Audet and Thomas 1996; Barclay et al. 1996; Willis and Brigham 2003). We clipped a small patch $\left(<1 \mathrm{~cm}^{2}\right)$ of fur between the shoulders and attached a temperature-sensitive radio-transmitter (0.9-1 g, BD-2NT; Holohil Systems Ltd, Carp, Ontario) using a latex cement (TORBOT Group, Inc., Cranston RI, USA). On average the body mass of bats affixed with transmitters was $14.5 \pm 1.5 \mathrm{~g}$ and transmitters 
represented between 5.6 and $7.5 \%$ of body mass. Individual bats were radio-tracked each morning to find day roosts using a scanning receiver (Australis 26K Scanning Receiver, Titley Electronics, Ballina, Australia) connected to a 3-element Yagi antenna. A data-logging receiver (Lotek SRX_800; Lotek Engineering Inc. Newmarket, Ontario, Canada) was deployed at roosts and recorded individual $T_{\mathrm{sk}}$ at 10-min intervals whenever a radio-tagged bat was present.

Thermoregulatory stages were classified following Jonasson and Willis (2011). Warming: an abrupt increase in torpid $T_{\text {sk }}$ (three consecutive recordings) that eventually stabilized at a normothermic level. Normothermic: the time between the end of the warming phase and the initiation of cooling. Cooling: readily obvious as a decline in $T_{\text {sk }}$ (three consecutive recordings) preceding steady-state torpor. Torpid: stable $T_{\mathrm{sk}}$ (three consecutive recordings) following the cooling phase and preceding the warming phase. We excluded data from the first $24 \mathrm{~h}$ after releasing the bats to avoid the influence of disturbance on our results. We recorded the date and time of each arousal from the $T_{\text {sk }}$ trace and converted the time of arousal to radians. We then used Rayleigh's test for circular distributions to determine if the daily distribution of arousal times was significantly different from random.

We recorded regular drops in $T_{\mathrm{sk}}$ during the normothermic phase which we refer to as shallow heterothermy, and did not meet our criteria for torpor (i.e. more than $30 \mathrm{~min}$ ). To compare normothermic bouts we calculated the Heterothermy Index: $\sqrt{\frac{\sum\left(\text { mean modal } T_{\text {sk }}-T_{\text {sk }}\right)^{2}}{n-1}}($ HI; Boyles et al. 2011). HI provides a single value for daily fluctuations in $T_{\mathrm{sk}}$, and can be used to quantify, and compare highly variable $T_{\mathrm{sk}}$ data.

To estimate energy savings associated with drops in $T_{\mathrm{sk}}$ during normothermia, we estimated power (energy consumption; $W$ ) of maintaining mean modal active $T_{\mathrm{sk}}\left(E_{\mathrm{mm}}\right)$, and estimated energy consumption of recorded $T_{\mathrm{sk}}\left(E_{\text {obsv }}\right)$. We assumed bat mass was $80 \%$ water, and estimated kilojoules using: $\mathrm{kJ}=$ (Mass) (specific heat capacity of water) $\left(T_{\mathrm{sk}}-T_{\mathrm{a}}\right)$. We assumed that $T_{\mathrm{sk}}$ and $T_{\mathrm{a}}$ remained constant during the 10 min recording interval, and then estimated energy consumption using: $W=(\mathrm{kJ} \mathrm{s})^{-1} 1000$, and daily energy consumption as the sum of these values. We subtracted daily $E_{\text {obsv }}$ from daily $E_{\mathrm{mm}}\left(E_{\text {diff }}\right)$ to estimate energy savings.

We recorded $T_{\mathrm{a}}$, barometric pressure $\left(P_{\mathrm{bar}}\right)$, and roost temperature $\left(T_{\text {roost }}\right)$ of one communal roost using data loggers (HOBO Micro Station Data Logger-H21-002, Onset Computer Corporation, Cape Cod, MA, USA). Ambient temperature was recorded in the shade, $2 \mathrm{~m}$ above the ground, and the logger inside the communal roost was placed $1 \mathrm{~m}$ inside the tree hole in a part of the cavity known to be used by bats.

To determine which bat-specific, and weather-specific variables best predict thermoregulatory strategy we used linear mixed effect models (LMEM). In bat-specific models, we used torpor bout duration $\left(\log _{10}\right)$ (to decrease the spread of residuals) and minimum $T_{\mathrm{sk}}$ as response variables, sex as a fixed effect, and individual as a random effect. In weather-specific models we used torpor bout duration $\left(\log _{10}\right)$, minimum $T_{\text {sk }}$, or $\mathrm{HI}$ as response variables, and three variables which have been associated with bat activity in past studies: (1) $T_{\mathrm{a}}$; (2) $T_{\text {roost }}$, which may be buffered and less variable compared to $T_{\mathrm{a}}$; (3) change in $P_{\mathrm{bar}}$, which reflects passing weather fronts and is correlated with both insect and bat activity (Jones et al. 1995). Temperature and especially $P_{\text {bar }}$ should rapidly equilibrate inside and outside the roost, and could be used by bats to assess relative levels of insect abundance.

All analyses were conducted in $\mathrm{R}$ studio version 0.98.945 (R Development Core Team 2009) and values are reported as the mean $\pm \mathrm{SD}$ with $\mathrm{n}$ representing the number of animals and $N$ the number of events/arousals. We assessed significance at the $P<0.05$ level.

\section{Results}

We attached transmitters to 8 individuals (5 males, 3 females) and recorded 61 bats-days of $T_{\mathrm{sk}}$ data from 7 individuals (4 males, 3 females). Neither body mass ( $P=0.65, t=-0.47, n=8$ individuals) nor BCI $(P=0.74, t=-0.35, n=8)$ differed between sexes. Individuals caught in the summer were heavier $(16 \pm 0.0 \mathrm{~g}$; $n=3 ; P<0.01, t=5.7)$ than those caught during winter $(14 \pm 0.8 \mathrm{~g} ; n=5)$, and had higher BCI $(P<0.01, t=6.1)$

Ambient temperature during summer varied between a mean minimum of $10.2 \pm 1.6{ }^{\circ} \mathrm{C}(N=18$, absolute minimum $=2.7{ }^{\circ} \mathrm{C}$ ) and mean maximum of $18.6 \pm 1.7{ }^{\circ} \mathrm{C}$ $\left(N=18\right.$, absolute maximum $\left.=22.3^{\circ} \mathrm{C}\right)$, with a mean daily range of $8.4 \pm 1.5^{\circ} \mathrm{C}\left(N=18\right.$, absolute range $\left.=11.5^{\circ} \mathrm{C}\right)$. During winter, $T_{\mathrm{a}}$ varied between a mean minimum of $5.6 \pm 2.3{ }^{\circ} \mathrm{C}\left(N=43\right.$, absolute minimum $\left.=-2.2{ }^{\circ} \mathrm{C}\right)$ and a mean maximum of $10.3 \pm 2.3{ }^{\circ} \mathrm{C}(N=43$, absolute maximum $=15.9^{\circ} \mathrm{C}$ ), with a mean daily range of $4.7 \pm 2.1{ }^{\circ} \mathrm{C}$ $\left(N=43\right.$, absolute range $10.1^{\circ} \mathrm{C}$; Fig. 1$)$.

During summer, mean minimum communal $T_{\text {roost }}$ $\left(13.2 \pm 1.5{ }^{\circ} \mathrm{C}\right)$ was higher than mean minimum $T_{\mathrm{a}}$ $\left(10.2 \pm 1.6{ }^{\circ} \mathrm{C}\right)$, and mean $T_{\text {roost }}$ range $(3.8 \pm 0.9)$ was smaller than mean $T_{\mathrm{a}}$ range $(8.4 \pm 1.5$; Table 1$)$. Mean daily solitary $T_{\text {roost }}\left(n=3\right.$ roosts, $N=12$ days; $\left.14.2 \pm 3.4^{\circ} \mathrm{C}\right)$ was higher than mean $T_{\mathrm{a}}\left(10.2 \pm 1.6{ }^{\circ} \mathrm{C}\right)$, and the mean $T_{\text {roost }}$ range (2.8 \pm 1.2$)$ was less than the mean $T_{\mathrm{a}}$ range $(4.6 \pm 1.5)$.

During summer and winter, $97.6 \%$ of torpor bouts occurred in solitary roosts (42/43) and only once in a communal roost. The HI for all bats was significantly higher (i.e. more heterothermic) when they roosted in solitary roosts $(19.5 \pm 4)$ compared to communal roosts $(3.2 \pm 3.6$, 


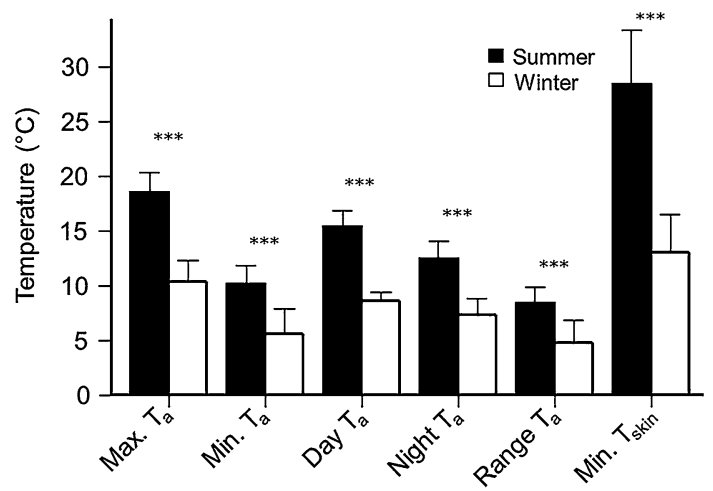

Fig. 1 Differences in temperature between summer (black bars) and winter (white bars). Max. $T_{\mathrm{a}}$ and Min. $T_{\mathrm{a}}$ are the means of all respective daily maximum and minimum ambient temperature $\left(T_{\mathrm{a}}\right)$; day $T_{\mathrm{a}}$ and night $T_{\mathrm{a}}$ are the means of all day and night $T_{\mathrm{a}}$ (sunrise to sunset, and sunset to sunrise); range $T_{\mathrm{a}}$ is the mean of all daily ranges in $T_{\mathrm{a}}\left(\max . T_{\mathrm{a}}-\min . T_{\mathrm{a}}\right.$ ); Min. $T_{\text {skin }}$ is the mean of all individuals mean minimum skin temperature. Values represent mean $\pm \mathrm{SD}$, asterisks represents a significant difference between seasons (Student's $t$ test; $P<0.05)$

Table 1 Communal and solitary roost thermal characteristics compared to corresponding ambient conditions in Pureora Forest Park

\begin{tabular}{lllll}
\hline & $\begin{array}{l}\text { Mean } T_{\mathrm{a}} \\
\left({ }^{\circ} \mathrm{C}\right)\end{array}$ & $\operatorname{Max} T_{\mathrm{a}}\left({ }^{\circ} \mathrm{C}\right)$ & $\operatorname{Min} T_{\mathrm{a}}\left({ }^{\circ} \mathrm{C}\right)$ & $\begin{array}{l}\text { Range } T_{\mathrm{a}} \\
\left({ }^{\circ} \mathrm{C}\right)\end{array}$ \\
\hline $\begin{array}{c}\text { Communal } \\
\text { roost }\end{array}$ & $14.7 \pm 1.4$ & $17.2 \pm 1.7$ & $13.2 \pm 1.5$ & $3.8 \pm 0.5$ \\
$\begin{array}{c}\text { Communal } \\
\text { ambient }\end{array}$ & $15.6 \pm 1.5^{\#}$ & $18.6 \pm 1.7^{*}$ & $10.2 \pm 1.6^{*}$ & $8.4 \pm 1.5^{*}$ \\
$\begin{array}{c}\text { Solitary } \\
\text { roost }\end{array}$ & $14.2 \pm 3.4$ & $15.4 \pm 3.0$ & $12.8 \pm 3.5$ & $2.8 \pm 1.1$ \\
$\begin{array}{c}\text { Solitary } \\
\text { ambient }\end{array}$ & $6.8 \pm 4.7^{*}$ & $8.8 \pm 4.5^{*}$ & $4.2 \pm 4.6^{*}$ & $4.6 \pm 1.5^{*}$ \\
\hline
\end{tabular}

Mean $T_{\mathrm{a}}$ is the average of all mean ambient temperatures $\left(T_{\mathrm{a}}\right)$; $\operatorname{Max} T_{\mathrm{a}}$ and Min $T_{\mathrm{a}}$ are the mean of all respective daily maxima and minima $T_{\mathrm{a}}$; Range $T_{\mathrm{a}}$ is the mean of all daily ranges in $T_{\mathrm{a}}\left(\max . T_{\mathrm{a}}-\min . T_{\mathrm{a}}\right)$. Values are mean $\pm \mathrm{SD}$, communal $N=18$ days, solitary $N=12$

* Significant difference between values (Student's $t$ test; $P<0.01$ ), ${ }^{\#}=0.098$

$P<0.01, t=-15.7, d f=35.8)$. During winter, bats used torpor on $95.3 \%$ of days and on $11.1 \%$ of observation days during summer (Fig. 2). Every individual entered torpor at least once in winter, while only one individual did so during summer. Torpor bout durations ranged from 0.9 to $2.2 \mathrm{~h}$ in summer and 6.7 to $120.8 \mathrm{~h}$ in winter.

Multiday torpor bouts made up $47.6 \%$ of torpor bouts (10/21) during winter and were not recorded during summer. Mean daily torpor bout duration during winter was $10.1 \pm 3.7 \mathrm{~h}(n=4, N=11)$ while mean multiday torpor duration was $60.7 \pm 27.5 \mathrm{~h}(n=4, N=10)$. Torpor bout duration $\left(\log _{10}\right)$ decreased with increasing $T_{\mathrm{a}}$ during winter $(P=0.02, t=-2.6$, ordinary least square (OLS)

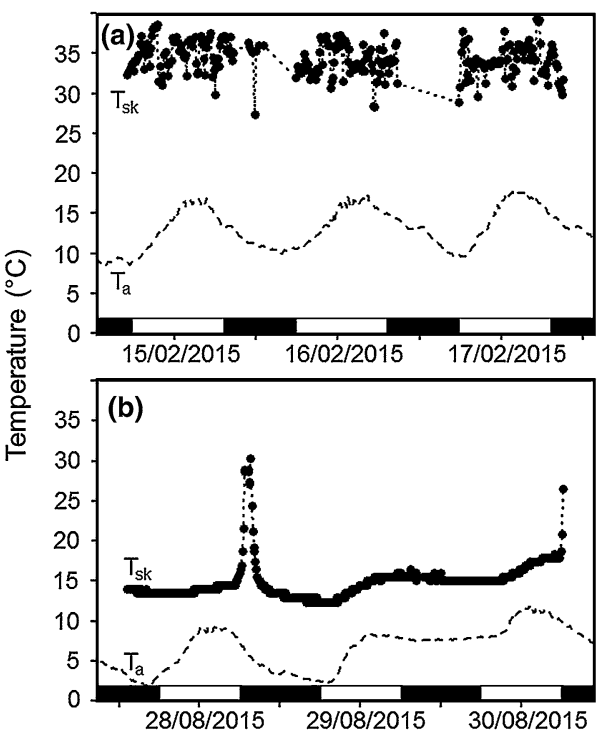

Fig. 2 Skin temperature ( $T_{\mathrm{sk}}$, upper trace, dotted line) and ambient temperature data ( $T_{\mathrm{a}}$, lower trace, dashed line) for two different $M$. tuberculata individuals, monitored over 3 days in a a communal roost during summer and $\mathbf{b}$ a solitary roost during winter. Black and white bars denote night and day, respectively

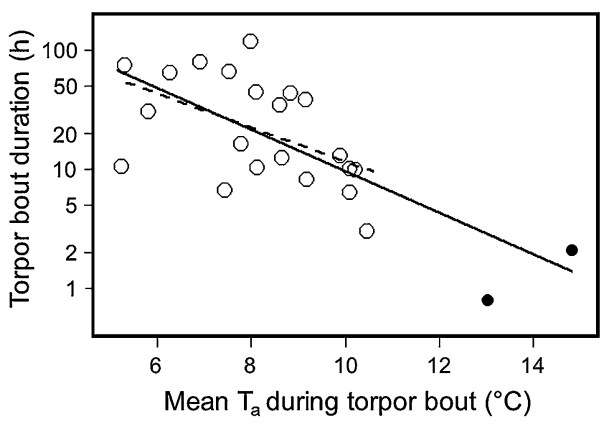

Fig. 3 Torpor bout duration (hours) of M. tuberculata as a function of mean $T_{\mathrm{a}}$ during torpor bout in summer (black circles) and winter (white circles). Winter torpor bout duration $\left(\log _{10}\right)$ decreased with increasing $T_{\mathrm{a}}$ (linear mixed effect model; $P=0.02, t=-2.6, N=3$ individuals, $n=16$ torpor bouts), dashed line represents ordinary least square regression of winter only torpor bouts $r^{2}=0.23$. Summer and winter torpor bout duration $\left(\log _{10}\right)$ decreased with increasing $T_{\mathrm{a}}$ (linear mixed effect model; $P<0.001, t=-4.7, N=4, n=18$ ), solid line represents ordinary least square regression of summer and winter torpor bouts $r^{2}=0.49$. Note log scale used on $y$-axis

$r^{2}=0.23$; Fig. 3). When torpor bout duration $\left(\log _{10}\right)$ and $T_{\mathrm{a}}$ from summer and winter were pooled and regressed together the $r^{2}$ value of this relationship was stronger $\left(P<0.001, t=-4.7\right.$, OLS $\left.r^{2}=0.49\right)$ compared to data from the winter-only.

Torpor bout duration did not differ between males and females $(P=0.8, t=-0.2, d f=9.6)$. During winter, females had lower minimum torpid $T_{\text {sk }} 11.9^{\circ} \mathrm{C}$ than 
males $14.8{ }^{\circ} \mathrm{C}(P=0.03, t=-2.3, d f=17)$, but were not exposed to significantly colder $T_{\mathrm{a}}(P=0.7, t=0.3$, $d f=32.7)$. The HI during days when bats did not use torpor was negatively correlated with the mean $T_{\mathrm{a}}(P<0.01$, $t=-5.9, d f=13$, OLS $r^{2}=0.69$, slope $\left.=-0.44\right)$ and the previous night's mean $T_{\mathrm{a}}(P<0.01, t=-4, d f=13$, OLS $r^{2}=0.53$, slope $=-0.54, n=4, N=18$ ). However, when removing the two winter days when bats did not enter torpor and analysing data for summer only, the relationship between mean $T_{\mathrm{a}}(P=0.01, t=-2.9, d f=12$, OLS $r^{2}=0.37$, slope $\left.=-0.37\right)$ remained significant but not the relationship between previous night's mean $T_{\mathrm{a}}(P=0.067$, $t=-2, d f=12$, OLS $r^{2}=0.23$, slope $=-0.32, n=3$, $N=16$ ).

We found that $E_{\text {diff }}$ was positively correlated with HI $\left(P<0.01, t=3.8, d f=13, n=4, N=18, r^{2}=0.45\right)$, i.e. more heterothermic behaviour lead to greater energy savings. The $r^{2}$ of this relationship increased when we analysed just the summer data $(P<0.01, t=5.1, d f=13, n=3$, $N=16$, OLS $\left.r^{2}=0.65\right)$. We found that $E_{\text {diff }}$ increased with decreasing mean $T_{\mathrm{a}}(P=0.02, t=-2.6, d f=13, n=4$, $n=18$, OLS $\left.\mathrm{R}^{2}=0.3\right)$ and the $r^{2}$ of this relationship increased when we analysed summer only data $(P=0.01$, $t=-3.0, d f=12, n=3, n=16$, OLS $r^{2}=0.39$ ).

The circular distribution of arousal times after torpor bouts was significantly non-random (Rayleigh $Z=19.8$, $P<0.001$, mean vector $=0.93, n=5, N=23$ ). Mean time of arousal was 18:13 $\pm 1: 31 \mathrm{~h}$ and arousals began $8.2 \pm 102.8 \min (n=5, N=23)$ before sunset. During winter, mean $T_{\mathrm{a}}$ on nights when bats aroused from torpor was higher $\left(7.9 \pm 2.1{ }^{\circ} \mathrm{C}\right)$ than on nights when bats remained torpid $\left(6.7 \pm 1.7{ }^{\circ} \mathrm{C}, P=0.045, t=-2.1\right.$, $d f=40$ ). None of the other weather variables we recorded differed between days bats remained torpid or aroused.

\section{Discussion}

We demonstrate that $M$. tuberculata exhibit seasonal roost choice, with a preference for communal roosts during summer and solitary roosts during winter. This agrees with our first hypothesis. We also found support for our second hypothesis, providing the first evidence that $M$. tuberculata is flexible in its seasonal energetic strategy, using prolonged torpor during winter and short bouts of torpor during summer and winter. In addition, torpor bout duration correlates negatively with mean $T_{\mathrm{a}}$. We found mixed support for our final hypothesis, as we did not find that females performed longer torpor bouts than males, but we did observe that females had lower minimum torpid $T_{\text {sk }}$. Our data indicate that individuals are more energetically stressed during winter than summer and suggests that they use buffered roosts and torpor to cope with presumed energy shortages.
Roost choice changed seasonally with $83 \%$ of nights spent in communal roosts during summer compared to $7 \%$ during winter. The thermal characteristics we recorded indicate that communal roosts are more thermally stable than $T_{\mathrm{a}}$ and buffer against extreme cold. In other parts of New Zealand M. tuberculata prefer thermally buffered communal roosts with large cavities during summer (Sedgeley 2003, 2006). Large cavities may allow for more conspecifics and the potential for greater social thermoregulation (Willis et al. 2006; although see Dausmann and Glos 2014). Roosts that are buffered and large enough for social thermoregulation may be ideal for reproductive females to leave young of the year which may be more susceptible to drastic $T_{\mathrm{a}}$ fluctuations. However, disturbance by roost mates can be detrimental, and impromptu arousals by roost mates may lead to unwanted energy expenditure which may be especially dangerous when energy reserves are low (Speakman et al. 1991; Turner et al. 2015). The preference for solitary roosts during winter may be driven by energetically stressed individuals avoiding the potential costs associated with communal living.

The preference by bats for solitary roosts during winter may reflect a need for buffered microclimates. For all hibernating animals there is a "set-point" temperature $\left(T_{\text {set }}\right)$ below which thermoregulation is initiated, metabolic rate increases and torpor bout duration decreases, and therefore, energy costs increase (Heller and Hammel 1972). In response to freezing $T_{\mathrm{a}}$ some hibernating individuals must perform costly emergency arousals (Humphries et al. 2003). To protect against temperatures below $T_{\text {set }}$ many species use insulated nests/roosts (Casey 1981; Schmid 1998; Buck and Barnes 1999). It is likely that during winter, individuals must seek out roosts to facilitate and enhance energy savings from torpor, but buffered against $T_{\mathrm{a}}$ below $T_{\text {set }}$. Although we could not determine the $T_{\text {set }}$ of $M$. tuberculata, we did record minimum torpid $T_{\text {sk }}$ of $8.6{ }^{\circ} \mathrm{C}$. We recommend future studies using open-flow respirometry to determine $M$. tuberculata's $T_{\text {set }}$ and behavioural tests to examine preferences in roost microclimate.

To balance the physiological costs of torpor with the energetic benefits, the torpor optimization hypothesis predicts that individuals with large energy stores should express less torpor than those with limited reserves. Mystacina tuberculata seem to employ both short and multiday torpor bouts during winter. During winter, bats used torpor more often, and these torpor bouts are deeper and more prolonged compared to summer. Similar to other insectivorous bats (Stawski and Geiser 2010; Park et al. 2000) torpor bout duration during winter correlated with $T_{\mathrm{a}}$ and individuals performed longer torpor bouts in response to colder $T_{\mathrm{a}}$. Temperatures $<10{ }^{\circ} \mathrm{C}$ are likely to constrain 
insect abundance which reduces foraging success and makes torpor a less risky energetic strategy compared to foraging (Park et al. 2000; Hope and Jones 2012). Despite relatively cold $T_{\mathrm{a}}$ during winter in 2015, warmer mean night $T_{\mathrm{a}}$ between 9 and $10{ }^{\circ} \mathrm{C}$ were not uncommon, which may provide conditions for greater insect abundance, and therefore, the opportunity to forage successfully. During summer, individuals likely have larger fat stores compared to winter, and therefore, do not need to rely on torpor due to improved fuel availability and insulation.

If torpor is employed, energy savings increase with a fall of $T_{\text {sk }}$. We found no sex differences in torpor bout duration during winter. However, we did find that female minimum torpid $T_{\mathrm{sk}}$ was lower than males despite no significant differences in the mean or minimum $T_{\mathrm{a}}$ they experienced. This agrees with predictions of the torpor optimization hypothesis for species with sex specific life history differences. Jonasson and Willis (2011) showed that male bats use their energy stores more rapidly than females during hibernation and their body mass declined (by as much as $130 \%$ ) faster relative to that of females. Male $M$. lucifugus, unlike females, do not need to conserve fat to fuel post-emergence pregnancy (Jonasson and Willis 2011). Female M. tuberculata are likely under greater pressure to enter the reproductive season with larger fat reserves to initiate pregnancy. Conversely, males are likely under less pressure to conserve energy during winter, and spend more energy than females during torpor, and potentially decrease costs of torpor by maintaining higher minimum $T_{\mathrm{sk}}$.

Weather conditions appear to influence the thermal strategies of normothermic individuals and our data lend further support to the torpor optimization hypothesis. We found that the HI for normothermic individuals correlated with mean $T_{\mathrm{a}}$, indicating that individuals were more heterothermic during colder days. Moreover, HI positively correlated with daily $E_{\text {diff }}$. Individuals using a greater degree of heterothermy would save more energy compared to individuals maintaining a stable $T_{\mathrm{b}}$. Though only an estimate, our model predicts that a $15 \mathrm{~g}$ individual in a $10{ }^{\circ} \mathrm{C}$ day-roost defending a $T_{\mathrm{b}}$ of $39.4{ }^{\circ} \mathrm{C}$ would spend $1.4 \mathrm{~kJ}$ while at $25.5^{\circ} \mathrm{C}$ it would spend only $0.78 \mathrm{~kJ}$. It would be useful for further studies in the laboratory to calculate metabolic rate under controlled conditions to better calculate the precise energy savings.

During winter, arousals from torpor were significantly non-random and occurred on significantly warmer nights. This suggests that individuals, while torpid, are able to use environmental cues from within their roost to assess ambient conditions. Greater horseshoe (Rhinolophus ferrumequinum) and Natterer's bats (Myotis nattereri) maintained a circadian pattern to arousals and synchronized arousals with sunset, likely to take advantage of mild winter nights and potential prey abundance (Hope and Jones 2012; Park et al. 2000). Aerial insect abundance can increase dramatically with mild $T_{\mathrm{a}}$ (Jones et al. 1995), providing opportunities to forage especially near dusk when flying insects are most abundant (Racey and Swift 1985). Our results suggest that during winter, individuals may track $T_{\text {a }}$ passively and arouse in response to nights which provide lower thermoregulatory costs and higher probability of successful foraging.

\section{Conclusions}

We show that M. tuberculata has a highly flexible seasonal energetic strategy despite relatively low seasonal variation in $T_{\mathrm{a}}$. During summer and winter, roosts are used that buffer against $T_{\mathrm{a}}$ fluctuations, and this is most important during winter. Our data suggest that, in the wild, M. tuberculata are facultative torpor users. While we cannot definitively state that $M$. tuberculata are hibernators, they clearly employ a continuum of heterothermic responses during summer and winter; from shallow heterothermy to multiday torpor bouts. Longer torpor bouts were correlated with colder $T_{\mathrm{a}}$ and were interrupted by arousals at sunset during significantly warmer evenings presumably for individuals to take advantage of milder conditions. These data agree with the torpor optimization hypothesis and it appears that individuals attempt to balance the physiological costs associated with torpor induction and cessation against energy savings of metabolic suppression in torpor. Our data also indicate that small mammals in warm temperate climates respond to relatively small changes in seasonal $T_{\mathrm{a}}$ with a similar energetic strategy as more cold temperate species. It will be interesting to compare populations of M. tuberculata from the cold temperate South Island of New Zealand to determine roost preference and thermoregulatory response to more extreme seasonal changes in $T_{\mathrm{a}}$, and the extent of the species' phenotypic plasticity and energetic flexibility.

Acknowledgments We thank C. Craig and J. Wilkins-Baigent for help with field work. New Zealand Department of Conservation for housing, the Pureora Field Base, specifically T. Thurley for essential logistical support. We also thank two anonymous reviewers whose comments on an earlier version greatly improved the quality of this manuscript. This study was funded by the University of Auckland and a Commonwealth Scholarship awarded to Z.C.

Author contribution statement ZJC, RMB and SP conceived and designed the study. ZJC conducted fieldwork, analysed the data, and wrote the manuscript; RMB, SP and AJRH provided editorial advice.

Compliance with ethical standards

Conflict of interest The authors declare that they have no conflict of interest. 


\section{References}

Arkins AM, Winnington AP, Anderson S, Clout MN (1999) Diet and nectarivorous foraging behaviour of the short-tailed bat (Mystacina tuberculata). J Zool (Lond) 247:183-187

Audet D, Thomas DW (1996) Evaluation of the accuracy of body temperature measurement using external radio transmitters. Can J Zool 74:1778-1781

Barclay RMR, Kalcounis MC, Crampton LH, Stefan C, Vonhof MJ, Wilkinson L, Brigham RM (1996) Can external radiotransmitters be used to assess body temperature and torpor in bats? J Mammal 77:1102-1106

Boyles JG, Brack JV (2009) Modeling survival rates of hibernating mammals with individual-based models of energy expenditure. J Mammal 90:9-16

Boyles JG, Smit B, McKechnie AE (2011) A new comparative metric for estimating heterothermy in endotherms. Physiol Biochem Zool 84:115-123

Buck CL, Barnes BM (1999) Temperatures of hibernacula and changes in body composition of arctic ground squirrels over winter. J Mammal 80:1264-1276

Casey TM (1981) Nest insulation: energy savings to brown lemmings using a winter nest. Oecologia 50:199-204

Christie JE (2003) Spatial and temporal activity patterns of lesser short-tailed bats (Mystacina tuberculata) in Fiordland. Unpublished MSc thesis, University of Otago, Dunedin, New Zealand

Christie JE (2006) Nocturnal activity patterns of the lesser short-tailed bats (Mystacina tuberculata) in temperate rainforest, Fiordland, New Zealand. N Z J Zool 33:125-132

Christie JE, Simpson W (2006) Influence of winter weather conditions on lesser short-tailed bat (Mystacina tuberculata) activity in Nothofagus forest, Fiordland. N Z J Zool 33:133-140

Csada RD, Brigham RM (1994) Reproduction constrains the use of daily torpor by free-ranging common poorwills (Phalaenoptilus nuttallii) (Aves, Caprimulgidae). J Zool 234:209-216

Daniel MJ (1979) The New Zealand short-tailed bat, Mystacina tuberculata; a review of present knowledge. N Z J Zool 6:357-370

Daniel MJ (1990) Order Chiroptera. In: King CM (ed) The handbook of New Zealand mammals. Oxford University Press, Auckland, pp 114-137

Dausmann KH, Glos J (2014) No energetic benefits from sociality in tropical hibernation. Funct Ecol 29:498-505

Davis WH, Hitchcock HB (1965) Biology and migration of the bat, Myotis lucifugus, in New England. J Mammal 46:296-313

Doucette LI, Brigham RM, Pavey CR, Geiser F (2012) Prey availability affects daily torpor by free-ranging Australian owlet-nightjars (Aegotheles cristatus). Oecologia 169:361-372

Geiser F (2004) Metabolic rate and body temperature reduction during hibernation and daily torpor. Annu Rev Physiol 66:239-274

Geiser F (2007) Yearlong hibernation in a marsupial mammal. Naturwissenschaften 94:941-944

Grigg GC, Beard LA, Augee ML (2004) The evolution of endothermy and its diversity in mammals and birds. Physiol Biochem Zool 77:982-998

Heller HC, Hammel HT (1972) CNS control of body temperature during hibernation. Comp Biochem Physiol A 41:349-359

Hope PR, Jones G (2012) Warming up for dinner: torpor and arousal in hibernating Natterer's bats (Myotis nattereri) studied by radio telemetry. J Comp Physiol B 182:569-578

Humphries MM, Thomas DW, Kramer DL (2003) The role of energy availability in mammalian hibernation: a cost-benefit approach. Physiol Biochem Zool 76:165-179

Jonasson KA, Willis CKR (2011) Changes in body condition of hibernating bats support the thrifty female hypothesis and predict consequences for populations with white-nose syndrome. PLoS One 6:e21061

Jones G, Duvergé PL, Ransome RD (1995) Conservation biology of an endangered species: field studies of greater horseshoe bats. Symp Zool Soc Lond 67:309-324

Körtner G, Geiser F (2000a) The temporal organization of daily torpor and hibernation: circadian and circannual rhythms. Chronobiol Int 17:103-128

Körtner G, Geiser F (2000b) Weather patterns and daily torpor in free-ranging animals. In: Heldmaier G, Klingenspor M (eds) Life in the cold: 11th international hibernation symposium. Springer, Berlin, pp 103-110

Lyman CP (1982) Who is who among the hibernators. In: Lyman CP, Willis JS, Malan A, Wang LCH (eds) Hibernation and torpor in mammals and birds. Academic Press, New York, pp 2-36

McNab BK (2002) The physiological ecology of the vertebrates: a view from energetics. Cornell University Press, Ithaca, pp $459-466$

Michener GR (1992) Sexual differences in over-winter torpor patterns of Richardson's ground squirrels in natural hibernacula. Oecologia 89:397-406

Paige KN (1995) Bats and barometric pressure: conserving limited energy and tracking insects from the roost. Funct Ecol 9:463-467

Park KJ, Jones G, Ransome RD (2000) Torpor, arousal and activity of hibernating Greater Horseshoe Bats (Rhinolophus ferrumequinum). Funct Ecol 14:580-588

Racey PA, Swift SM (1985) Feeding ecology of Pipistrellus pipistrellus (Chiroptera: Vespertilionidae) during pregnancy and lactation. I. Foraging behaviour. J Anim Ecol 54:205-215

R Development Core Team (2009) R: a language and environment for statistical computing. $\mathrm{R}$ foundation for statistical computing, Vienna, Austria. ISBN 3-900051-07-0. http://www.R-project.org

Ruf T, Geiser F (2015) Daily torpor and hibernation in birds and mammals. Biol Rev 90:891-926

Schmid J (1998) Tree holes used for resting by Gray Mouse Lemurs (Microcebus murinus) in Madagascar: insulation capacities and energetic consequences. Int J Primatol 19:797-809

Sedgeley JA (2003) Roost site selection and roosting behaviour in lesser short-tailed bats (Mystacina tuberculata) in comparison with long-tailed bats (Chalinolobus tuberculatus) in Nothofagus forest, Fiordland. N Z J Zool 30:227-241

Sedgeley JA (2006) Roost site selection by lesser short-tailed bats (Mystacina tuberculata) in mixed podocarp-hardwood forest, Whenua Hou/Codfish Island, New Zealand. N Z J Zool 33:97-111

Song X, Geiser F (1997) Daily torpor and energy expenditure in Sminthopsis macroura: interactions between food and water availability and temperature. Physiol Zool 70:331-337

Speakman JR, Webb PI, Racey PA (1991) Effects of disturbance on the energy expenditure of hibernating bats. J Appl Ecol 28:1087-1104

Stawski C, Geiser F (2010) Seasonality of torpor patterns and physiological variables of a free-ranging subtropical bat. J Exp Biol 213:393-399

Thomas DW, Dorais M, Bergeron JM (1990) Winter energy budgets and cost of arousals for hibernating little brown bats, Myotis lucifugus. J Mammal 71:475-479

Turner JM, Warnecke L, Wilcox A, Baloun D, Bollinger TK, Misra V, Willis CKR (2015) Conspecific disturbance contributes to altered hibernation patterns in bats with white-nose syndrome. Physiol Behav 140:71-78

Wallace J (2006) Short-tailed bats in Pikiariki Ecological Area, Pureora Forest Park. Unpublished Report. Pureora Field Centre, Department of Conservation 
Wang LCH (1989) Ecological, physiological, and biochemical aspects of torpor in mammals and birds. In: Wang LCH (ed) Advances in comparative and environmental physiology. Springer, Berlin, pp 361-401

Willis CKR, Brigham RM (2003) Defining torpor in free-ranging bats: experimental evaluation of external temperature-sensitive radio transmitters and the concept of active temperature. J Comp Physiol B 173:379-389

Willis CKR, Voss CM, Brigham RM (2006) Roost selection by forest-living female big brown bats (Eptesicus fuscus). J Mammal $87: 345-350$ 